\title{
7 Year Study on Perioperative Glucose Targets and Post-operative Surgical Site Infection and Mortality
}
Shanice Ker ${ }^{1}$, Roderica $\mathrm{Ng}^{2}$, Tan Teing Ee ${ }^{3}$, Sophia TH Chew ${ }^{4}$
${ }^{1}$ Yong Loo Lin School of Medicine, National University of Singapore
2Department of Anaesthesiology, Singapore General Hospital
${ }^{3}$ National Heart Centre, Singapore, Singapore General Hospital
${ }^{4}$ Cardiovascular and Metabolic Disorders, Duke-NUS Graduate Medical School
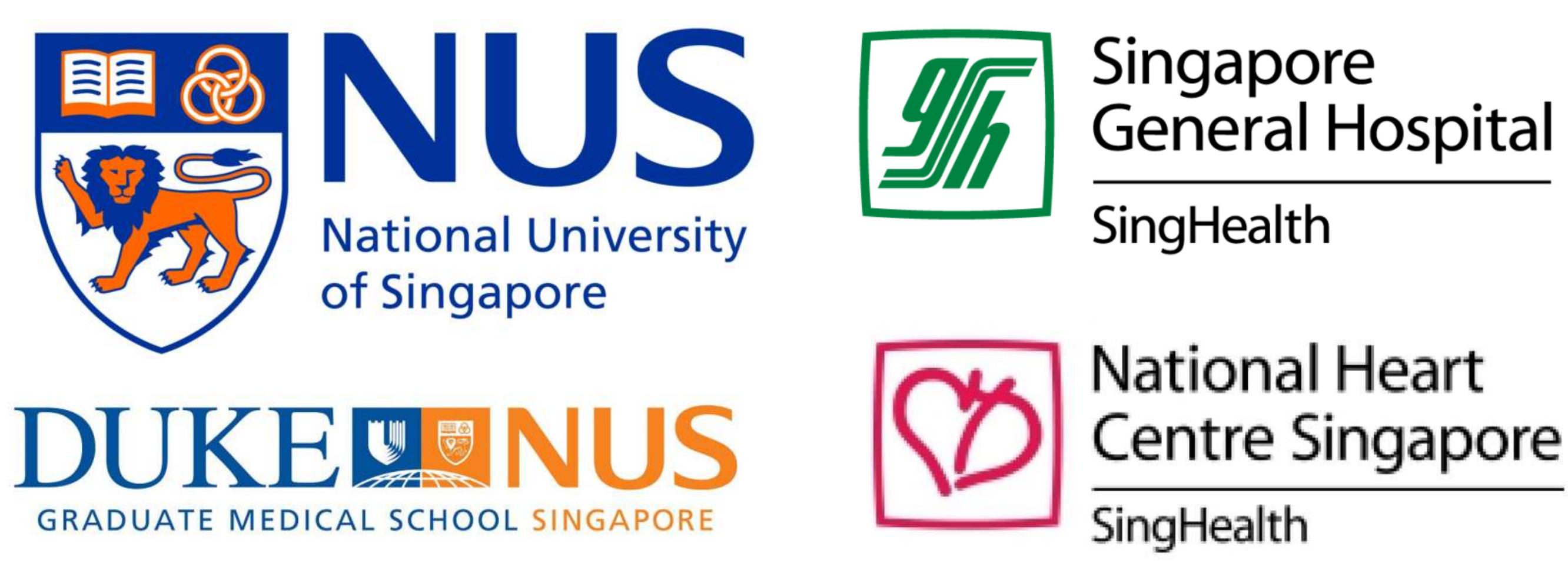

\section{INTRODUCTION AND BACKGROUND}

Perioperative hyperglycemia is associated with increased morbidity and mortality in cardiac surgical patients.

Intensive insulin therapy to maintain blood glucose below $6.1 \mathrm{mmol}$ reduced mortality and morbidity in critically ill patients but is associated with risks of hypogylcemia. As such the most recent guideline from Society of Thoracic Surgeons recommends a less stringent level of less than $10 \mathrm{mmol} / \mathrm{l}$.

A quality improvement project in accordance with these guidelines was initiated to keep target glucose between 4$8 \mathrm{mmol} / \mathrm{L}$ peri-operatively in 2009-2010 and thereafter to 4$10 \mathrm{mmol} / \mathrm{L}$. However, the association of these changing glucose targets with surgical site infection (SSI) and mortality remains to be elucidated. This 7 year audit aims to determine if changing target glucose levels affect the incidence of SSI and mortality amongst Asian patients undergoing CABG.

\section{METHODS}

All patients who underwent CABG surgery at our Centre were placed on insulin infusions titrated to achieve perioperative target glucose levels of $4-8 \mathrm{mmol} / \mathrm{l}$ in $2009-2010$ and $4-10 \mathrm{mmol} / \mathrm{l}$ from 2011. The first glucose upon arrival in the cardiothoracic intensive care unit (CTSICU) was recorded and entered into a cardiac anaesthesia database. Outcomes were incidence of SSI and mortality over the 7 year period.

\section{RESULTS}

4925 patients underwent CABG over this 7-year period. The mean first glucose level upon arrival in CTSICU was within target of $4-10 \mathrm{mmol} / /$ with no significant variation. Patients undergoing CABG were mainly male, Chinese, hypertensive, with a Euroscore of 2.2. Prevalence of diabetic patients was approximately $50 \%$. The prevalence of diabetic patients amongst those with SSI was $62 \%$, and the prevalence of patients with hypertension is $65 \%$. (Figure 1) The average SSI rate was $3.14 \%$ in 2008 which fell to $1.65 \%$ after initiation of the project, remaining stable thereafter. There was no association between glucose control and mortality. (Figure 2)

7 Year Trend of Post-Operative Surgical Site Infection and Mortality

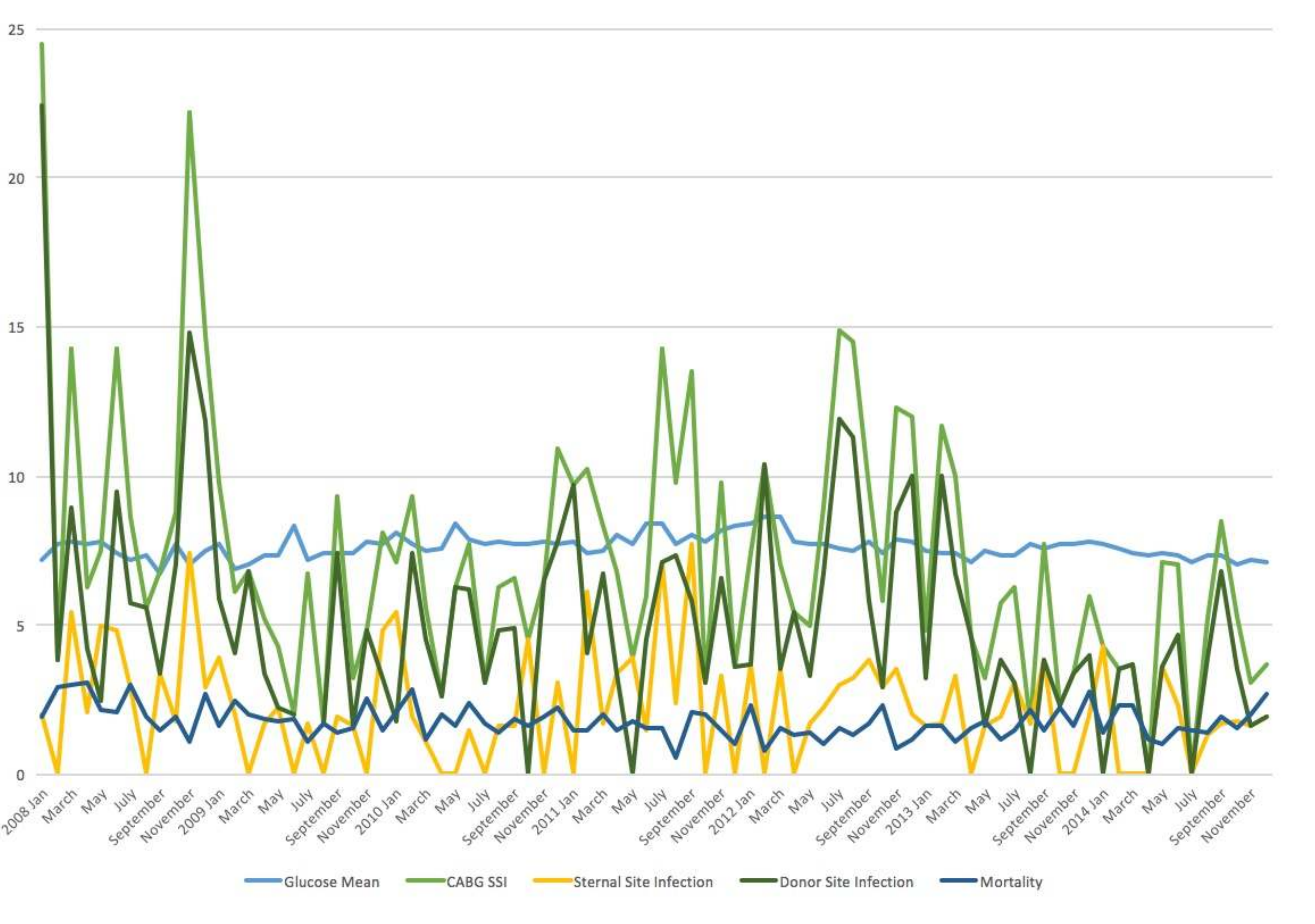

Figure 2. Run chart of 7 year post-operative outcomes

\section{DISCUSSION AND CONCLUSION}

Glucose targets were maintained throughout, with the implementation of the insulin regime and were sustained throughout the 7 years, hence the Hawthorne effect can be dismissed. There was a fall in the incidence of SSI at the beginning of the project, but no further fall thereafter. Other factors may be more important once the glucose levels are optimised. Mortality remained low and was not associated with change in glucose targets.

\section{REFERENCES}

1. Furnary AP et al. J Thorac Cardiovasc Surg 2003.

2. $\mathrm{Ng} \mathrm{RR}$ et al. J Thorac Cardiovasc Surg 2014.

3. Greet Van den Berghe et al. N Engl J Med 2001.

4. S. Strahan et al. Asian Cardiovas Thorac Ann 2012 